\title{
Self-reported fever, treatment actions and malaria infection prevalence in the northern states of Sudan
}

\author{
Khalid A Elmardi ${ }^{1}$, Abdisalan M Noor ${ }^{2,3^{*}}$, Sophie Githinji ${ }^{2}$, Tareg M Abdelgadir ${ }^{1}$, ElFatih M Malik ${ }^{4}$ and \\ Robert W Snow ${ }^{2,3}$
}

\begin{abstract}
Background: The epidemiology of fevers and their management in areas of low malaria transmission in Africa is not well understood. The characteristics of fever, its treatment and association with infection prevalence from a national household sample survey in the northern states of Sudan, an area that represents historically low parasite prevalence, are examined in this study.
\end{abstract}

Methods: In October-November 2009, a cluster sample cross-sectional household malaria indicator survey was undertaken in the 15 northern states of the Sudan. Data on household assets and individual level information on age, sex, whether the individual had a fever in the last 14 days and on the day of survey, actions taken to treat the fever including diagnostic services and drugs used and their sources were collected. Consenting household members were asked to provide a finger-prick blood sample and examined for malaria parasitaemia using a rapid diagnostic test (RDT). All proportions and odds ratios were weighted and adjusted for clustering.

Results: Of 26,471 respondents $19 \%(n=5,299)$ reported a history of fever within the last two weeks prior to the survey and $8 \%$ had fever on the day of the survey. Only $39 \%(n=2,035)$ of individuals with fever in last two weeks took any action, of which $43 \%(n=875)$ were treated with anti-malarials. About $44 \%(n=382)$ of malaria treatments were done using the nationally recommended first-line therapy artesunate+sulphadoxinepryrimethamine (AS+SP) and 13\% $(n=122)$ with non-recommended chloroquine or SP. Importantly 33.9\% $(n=$ 296) of all malaria treatments included artemether monotherapy, which is internationally banned for the treatment of uncomplicated malaria. About $53 \%$ of fevers had some form of parasitological diagnosis before treatment. On the day of survey, 21,988 individuals provided a finger-prick blood sample and only 1.8\% were found positive for Plasmodium falciparum. Infection prevalence was higher among individuals who had fever in the last two weeks $(\mathrm{OR}=3.4 ; 95 \% \mathrm{Cl}=2.6-4.4, \mathrm{p}<0.001)$ or reported fever on the day of survey $(\mathrm{OR}=6.2 ; 95 \% \mathrm{Cl}=4.4-8.7, \mathrm{p}<$ 0.001) compared to those without a history of fever.

Conclusion: Across the northern states of the Sudan, the period prevalence of fever is low. The proportion of fevers that are likely to be malaria is very low. Consequently, parasitological diagnosis of all fevers before treatment is an appropriate strategy for malaria case-management. Improved regulation and supervision of health workers is required to increase the use of diagnostics and remove the practice of prescribing artemisinin monotherapy.

\footnotetext{
* Correspondence: anoor@nairobi.kemri-wellcome.org

${ }^{2}$ Malaria Public Health \& Epidemiology Group, Centre for Geographic

Medicine Research - Coast, Kenya Medical Research Institute/Wellcome Trust

Research Programme, P.O. Box 43640, 00100 GPO, Nairobi, Kenya

Full list of author information is available at the end of the article
} 


\section{Background}

The diagnosis and treatment of fevers in Africa is undergoing a paradigm shift, away from the widely promoted concept that all fevers should be regarded as malaria [1-6] to more informed guidelines that promote the use of parasitological diagnostics and a rational use of artemisinin-based combination therapies [7]. This migration from presumptive to parasitological confirmed diagnosis is for a combination of reasons: the costs of replacement therapies for failed monotherapy [8], the recognition that parts of Africa are undergoing an epidemiological transition that supports Plasmodium falciparum transmission intensities considerably lower than ten years previously with a natural consequence that most fevers are not associated with malaria infection [9-11] and a more general ambition to improve the standards and quality of malaria case-management and its corollary that non-malaria febrile conditions receive better investigation, intervention and prognosis, and the advent of rapid diagnostic tests [7,12-15].

However, the understanding of the epidemiology of fevers and their management in areas where parasite exposure is infrequent is limited. Research into the epidemiology of malaria and understanding the impacts of control and disease management have traditionally focused on stable, high transmission areas of Africa. This study investigates the characteristics of fever management and infection prevalence from a national household survey in the northern states of Sudan, an area of historically low malaria risk.

\section{Methods}

\section{Malaria in the northern states of Sudan}

Over 27 million people live in the 15 northern states of Sudan with the National Malaria Control Programme based in Khartoum responsible for the implementation of federal policies and guidelines for malaria control. Stable, malaria transmission to both P. falciparum and Plasmodium vivax has historically been constrained by the arid climate among the most northern states that border Egypt [16-18]. In 2007, it was estimated that 5.7 million people were exposed to stable falciparum and to limited vivax malaria transmission in the northern states of Sudan $[19,20]$, with a highly over-distributed pattern of risk that was generally characterized by low parasite prevalence $[19,21]$. In 2005, a household sample survey reported an overall $P$. falciparum infection prevalence of $3.7 \%$ among all age groups using microscopy and a 14-day period prevalence of selfreported fever of $37 \%$ in eight northern states [21]. Despite the low prevalence of malaria infection it has been estimated that over $50 \%$ of all fevers are managed as malaria [22,23]. By 2006, malaria was thought to contribute to $50 \%$ of all out-patient diagnoses reported as part of the Health Information System of the northern states of the Sudan and accounted for an estimated 44,000 deaths in 2002 [18].

Against a background of escalating chloroquine resistant P. falciparum [24,25], northern states of the Sudan changed their treatment policy to artemisinin-based combination therapy (ACT) in June 2004 [26]. The current standard treatment protocol for uncomplicated falciparum malaria is artesunate plus sulphadoxine/ pyrimethamine $(\mathrm{AS}+\mathrm{SP})$, as first-line and artemetherlumefantrine $(\mathrm{AL})$ as second-line of treatment [23,27]. Overseas development assistance to support scaling up of malaria control activities rose sharply in 2004 with support from the Global Fund for AIDS, TB and Malaria (GFATM) approved malaria funding and by 2009 approximately $\$ 33$ million had been disbursed by the GFATM [28] to support malaria activities across the northern states of the Sudan. Since 2005, the Sudan national malaria control programme (NMCP) has distributed over 6 million long-lasting insecticide treated nets, expanded residual insecticide spraying of houses in selected areas; and supported the improvement of malaria case-management through in-service training of health workers in revised standard treatment guidelines and increased use of diagnostics and improving the supply of AS+SP to over $90 \%$ of government health facilities.

\section{Household malaria survey}

A household sample survey of basic malaria coverage indicators was undertaken between October and November 2009 across the northern 15 states of Sudan. A sample of 6,000 households across 300 clusters was selected using a multi-stage probability proportional to size (PPS) cluster sample design. The number of households required was determined using the Roll Back Malaria Monitoring and Evaluation Reference Group for indicators in young children (RBM-MERG) approach [29] with survey powered to detect changes in the proportion of children under the age of five years sleeping under an ITN with precision at the national and state levels. As a compromise between precision and logistics, an average of 20 households per clusters was used to estimate the number of sampling units to survey. To identify the location of the clusters to be surveyed a list of Popular Administrative Units (PAUs) from the National Statistics and Census Office (NSCO) was used to determine the PAUs in which survey clusters would be located. The PAUs in each state were selected according to PPS method distributed proportionately into urban and rural within each state as defined during the 2008 national census. The list and size of all enumeration areas (EAs) within the selected PAU was then assembled by the NSCO and a further sampling to 
select the clusters (EAs) to be surveyed was undertaken using the PPS method separately for urban and rural. Within each cluster, 20 households were randomly selected and all members of the households visited at the time of survey were interviewed using the relevant survey questionnaire.

A community sensitization exercise was undertaken a few weeks before and throughout the survey period in the print, radio and television media by the NMCP of the Federal Ministry of Health. Thirty coordinators selected at national and state levels were trained to be in-charge of the day-to-day management of the survey in their respective states. A total of 196 field team members (28 teams) were trained on general interviewing skills, administration of consent forms, filling of questionnaires, collection of blood samples, and appropriate treatment of individuals found positive for malaria. The team members were also trained in the use of global positioning systems for mapping of clusters. Each of the 28 survey teams, consisting of seven persons (one supervisor; two interviewers; two nurses or equivalent; and two laboratory technicians) visited one cluster per day.

A household members' questionnaire was adapted from the standard RBM-MERG tools [29] to ensure information was collected from all age groups. The questionnaire was developed first in English and translated into Arabic and draft versions were checked and piloted independently by members of the survey teams conversant in both languages to reduce ambiguities in translation. This questionnaire captured information on each usual and visiting resident member at household during the survey. Information including: age, sex, educational status, relationship to the head of the household, use of mosquito nets and insecticide-treated nets (ITN) the night prior to the survey, whether the room slept in last night had been subject to residual spraying in the last 12 months, and whether the individual had had a fever in the last 14 days were captured. Additional information was collected on whether the fever was present on the day of the survey, actions taken to treat the fever including diagnostic services used, drugs used and their sources. At the end of each interview each household member was asked to provide a finger prick blood sample following informed consent and examined for malaria parasitaemia using an RDT (First Response Malaria Ag (pLDH/HRP2) COMBO, Premier Medical Corporation Ltd). The test gave results on whether infection was due to $P$. falciparum or mixed species but did not distinguish between $P$. falciparum and $P$. vivax. At the end of each survey day, all questionnaires and RDTs were submitted to the state coordinators for review and storage. The state coordinators reviewed the survey team's daily submissions and suggested corrections where necessary.

\section{Data entry and analysis}

Twenty trained data entry personnel were hired to capture information from the survey questionnaires using customized data entry screens developed in Microsoft Access 2007. Once entered, data were checked for consistencies by a data manager and correctable errors reconciled.

Reports of fever were classified into two categories; those who reported to have had a fever in the last two weeks preceding the survey and those who reported fever present on the survey day. Treatment actions and drug classes were classified as first actions only. Common across all malaria indicator surveys, discerning multiple treatment sources, their sequence and timing has proved complex and difficult to interpret. Where surveys have investigated multiple treatment actions the first action is usually the dominant reported action and second or third actions are relatively rarely reported [30,31]. Descriptive analysis of fever and infection prevalence was undertaken according to age, sex, rural-urban residence, use of ITN and wealth quintile. All data were analyzed using STATA version 11.0 (StatCorp, College Station, Texas). All proportions and odds ratios were weighted and adjusted for clustering using the svy: command in STATA. Because the selection of the PAUs and the clusters was done probability proportional to size, sample weighting was implemented only at the household level and weights were derived as the inverse of the probability of selecting a household within a cluster. Multivariate regression models were fitted using the svy: logistic command allowing for clustering and weighting of the data to assess the association of fever as a risk factor for malaria infection. The analysis controlled this association for age, residence, use of ITN, and wealth quintile. For each predictor the Odds Ratio (OR), 95\% confidence interval $(\mathrm{CI})$, and P-values were recorded.

\section{Ethical considerations}

Ethical clearance was provided by the National Research Ethics Committee of the Federal Ministry of Health (fmoh/rd/SEC/09, date: 7/9/2009). All household members and parents/guardians fo children were informed about all relevant aspects of the study including its aim, procedures, potential risk and hazards. A signed informed consent was obtained and assurance given that the participation in the study was strictly voluntary and all information would remain confidential and anonymized. Persons who volunteered a blood sample for RDT malaria testing and were found positive were treated immediately by survey nurses using nationally recommended $\mathrm{AS}+\mathrm{SP}$ age-defined dosage.

\section{Results}

\section{Survey characteristics}

A total of 5,980 of 6,000 sampled households were surveyed from 300 clusters. 26,471 individuals from the 
households were available for interview during the survey. $55.7 \%$ of surveyed individuals were female, $19.4 \%$ were children under five years of age and $64.3 \%$ were from rural areas. About $83 \%(n=21,988)$ of the individuals provided a finger prick blood sample for testing malaria parasites while the rest refused to provide blood samples following informed consent and requests for voluntary participation.

\section{Epidemiological features of reported fever and infection prevalence}

Among all surveyed individuals, 19\% reported a history of fever in the last two weeks preceding the survey date and $8 \%$ were febrile on the day of survey (Table 1 , Additional File 1). There were very small differences with age, however female and rural residents had higher fever prevalence (in the last two weeks or on the day of survey) compared to male and urban residents respectively (Table 1). Fever prevalence was more than two times higher among individuals from the poorest household compared to those from the least poor households. Among the 21,988 individuals who volunteered a blood sample for RDT examination for the presence of malaria infection only $1.8 \%$ were found positive (Table 2 , Additional File 1). It is assumed that the majority of these infections were $P$. falciparum however it is not possible to disaggregate vivax or other Plasmodium infections from the reported positive cases. There was minimal age pattern in infection prevalence (Table 2). The prevalence of infection was higher in rural areas $(2.4 \%)$ compared to urban residents $(0.8 \%)$; among those who did not use nets $(2.4 \%)$ compared to those who did (1.6\%) and among individuals from the poorest households $(2.7 \%)$ compared to the least poor $(2.7 \%)$. Importantly, the

Table 1 Prevalence of fever in last two weeks, on the day of survey and treatment seeking $(\mathrm{N}=\mathbf{2 6 , 4 7 1 )}$ and malaria infection tested using rapid diagnostic tests $(\mathrm{N}=21,988)$ by gender, age, residence, used of insecticide treated nets (ITN) and wealth quintile

\begin{tabular}{|c|c|c|c|c|c|}
\hline & \multirow{2}{*}{$\begin{array}{r}\text { Number of } \\
\text { persons } \\
\text { interviewed }\end{array}$} & \multicolumn{3}{|r|}{ Fever } & \multirow[b]{2}{*}{$\begin{array}{r}\text { Positive \% }(95 \% \mathrm{Cl}) \\
(\mathrm{n} / \mathrm{N}=489 / 21,988) \\
* 2 \\
\end{array}$} \\
\hline & & $\begin{array}{r}\text { Fever last } 2 \text { weeks \% } \\
(95 \% \mathrm{Cl})(\mathrm{n} / \mathrm{N}=5,299 / \\
26471)\end{array}$ & $\begin{array}{r}\text { Fever on survey day } \% \\
(95 \% \mathrm{Cl})(\mathrm{n} / \mathrm{N}=2,370 / \\
2,6471)\end{array}$ & $\begin{array}{r}\text { Fevers for which treatment } \\
\text { was sought }(\mathrm{n} / \mathrm{N}=2,035 / \\
5,299)\end{array}$ & \\
\hline \multicolumn{6}{|l|}{ Gender } \\
\hline Male & 11,720 & $16.8(15.6-17.9)$ & $7.3(6.4-8.1)$ & $42.6(39.2-46.0)$ & $2.1(1.6-2.7)$ \\
\hline Female & 14,751 & $20.9(19.6-22.2)$ & $9.1(8.3-10.0)$ & $36.7(34.2-39.2)$ & $1.5(1.1-2.0$ \\
\hline \multicolumn{6}{|l|}{${ }^{* 1} \mathrm{Age}$} \\
\hline$<1$ & 1,148 & $20.7(18.3-23.3)$ & $11.0(8.9-13.2)$ & $45.2(37.7-52.6)$ & $2.1(1.1-3.2)$ \\
\hline $1-4$ & 3,982 & $23.3(21.3-25.3)$ & 7.8 (6.6-9.0) & $44.2(40.1-48.2)$ & $2.0(1.2-2.9)$ \\
\hline $5-9$ & 4,145 & $15.9(14.3-17.5)$ & $7.1(6.0-8.2)$ & $40.2(35.0-45.3)$ & $3.0(2.0-4.0)$ \\
\hline $10-19$ & 5,432 & $14.5(13.1-15.8)$ & $5.9(5.0-6.9)$ & $37.0(32.6-41.4)$ & $2.1(1.4-2.8)$ \\
\hline$>19$ & 11,764 & $20.6(19.4-21.8)$ & 9.7 (8.9-10.6) & $37.0(34.4-39.6)$ & $1.1(0.8-1.4)$ \\
\hline \multicolumn{6}{|l|}{ Residence } \\
\hline Urban & 9459 & $16.1(14.3-17.9)$ & $6.9(5.6-8.2)$ & $46.1(42.6-49.6)$ & $0.8(0.5-1.1)$ \\
\hline Rural & 17,012 & $21.2(19.5-22.9)$ & $9.4(8.3-10.5)$ & $35.0(31.7-38.2)$ & $2.4(1.7-3.2)$ \\
\hline \multicolumn{6}{|l|}{$\begin{array}{l}\text { Use of } \\
\text { ITN }\end{array}$} \\
\hline No & 23,377 & $18.6(17.5-19.8)$ & $7.9(7.2-8.7)$ & $38.9(36.3-41.6)$ & $2.4(1.2-3.6)$ \\
\hline Yes & 3,094 & $22.2(20.0-24.5)$ & $11.1(9.2-13.1)$ & $39.5(34.7-44.4)$ & $1.6(1.2-2.1)$ \\
\hline \multicolumn{6}{|l|}{$\begin{array}{l}\text { Wealth } \\
\text { quintile }\end{array}$} \\
\hline Least Poor & 5,649 & $13.6(12.0-15.3)$ & $4.3(3.3-5.2)$ & $53.0(48.6-57.4)$ & $0.4(0.2-0.7)$ \\
\hline Second & 5,776 & $14.9(13.3-16.4)$ & $5.9(4.8-7.1)$ & $44.2(39.5-48.9)$ & $1.1(0.7-1.6)$ \\
\hline Third & 5,183 & $21.4(19.2-23.7)$ & $9.9(8.3-11.6)$ & $40.6(36.4-44.8)$ & $1.9(1.1-2.6)$ \\
\hline Fourth & 5,006 & $22.3(20.0-24.8)$ & $10.9(9.2-12.7)$ & $34.5(30.4-38.5)$ & $3.3(1.7-4.9)$ \\
\hline Most Poor & 4,857 & $26.4(23.3-29.5)$ & $12.8(10.8-14.7)$ & $27.2(22.8-31.6)$ & $2.7(1.5-4.0)$ \\
\hline Total & 26,471 & $19.1(17.9-20.2)$ & $8.3(7.6-9.1)$ & $39.1(36.6-41.5)$ & $1.8(1.3-2.2)$ \\
\hline
\end{tabular}


Table 2 Results of multivariate regression analysis of the association of fever with malaria when controlled for gender, age, residence, use of insecticide treated nets (ITN) and wealth quintile

\begin{tabular}{|c|c|c|}
\hline & $\begin{array}{r}\text { Fever two weeks } \\
\text { included: Odds Ratio } \\
(95 \% \mathrm{Cl}), \mathrm{p} \text {-value }\end{array}$ & $\begin{array}{r}\text { Fever on the day of survey } \\
\text { included: Odds Ratio ( } 95 \% \\
\text { CI), p-value }\end{array}$ \\
\hline \multicolumn{3}{|l|}{$\begin{array}{l}\text { Fever in } \\
\text { the last } \\
\text { two weeks }\end{array}$} \\
\hline No & Ref. & \\
\hline Yes & $3.4(2.6-4.4),<0.001$ & \\
\hline \multicolumn{3}{|l|}{$\begin{array}{l}\text { Fever on } \\
\text { the day of } \\
\text { survey }\end{array}$} \\
\hline No & - & Ref. \\
\hline Yes & - & $6.2(4.4-8.7),<0.001$ \\
\hline \multicolumn{3}{|l|}{ Gender } \\
\hline Male & Ref. & Ref. \\
\hline Female & $0.7(0.6-0.9), 0.013$ & $0.7(0.6-0.9), 0.017$ \\
\hline \multicolumn{3}{|l|}{${ }^{* 1}$ Age } \\
\hline$<1$ & Ref. & Ref. \\
\hline $1-4$ & $1.0(0.5-1.8), 0.935$ & $1.1(0.6-2.1), 0.723$ \\
\hline $5-9$ & $1.7(0.9-3.1), 0.074$ & $1.8(0.9-3.1), 0.054$ \\
\hline $10-19$ & $1.4(0.8-2.7), 0.255$ & $1.6(0.8-2.9), 0.173$ \\
\hline$>19$ & $0.6(0.4-1.2), 0.150$ & $0.7(0.4-1.2), 0.143$ \\
\hline \multicolumn{3}{|l|}{ Residence } \\
\hline Urban & Ref. & Ref. \\
\hline Rural & $1.7(1.1-2.9), 0.037$ & $1.9(1.1-3.2), 0.022$ \\
\hline \multicolumn{3}{|l|}{ Use of ITN } \\
\hline No & Ref. & Ref. \\
\hline Yes & $1.4(0.8-2.2), 0.201$ & $1.4(0.8-2.2), 0.221$ \\
\hline \multicolumn{3}{|l|}{$\begin{array}{l}\text { Wealth } \\
\text { quintile }\end{array}$} \\
\hline Least Poor & Ref. & Ref. \\
\hline Second & $2.2(1.2-4.1), 0.015$ & $2.0(1.1-3.8), 0.031$ \\
\hline Third & $3.0(1.6-5.7), 0.001$ & $2.7(1.4-5.1), 0.003$ \\
\hline Fourth & $4.6(2.3-9.5),<0.001$ & $4.0(1.9-8.5),<0.001$ \\
\hline Most Poor & $3.4(1.6-7.5),<0.002$ & $2.9(1.4-6.5), 0.007$ \\
\hline
\end{tabular}

*1 14 individuals did not have age data; Ref. $=$ reference.

multivariate regression showed that after adjusting for gender, age, residence, use of ITN and wealth quintile, individuals who reported fever in the last two weeks and on the day of survey were three times (Odds Ratio (95\% confidence interval) 3.4 (2.6-4.4)) and 6 times (OR (95\% CI) 6.2 (4.4-8.7)) more likely to have malaria infection (Table 2). Interestingly, use of ITN was not significantly associated with the likelihood of having malaria infection.

Treatment actions for fever, access to diagnostic facilities and associations with infection prevalence

Among the 5,299 self-reported fevers occurring during the 14 days prior to the survey $39 \%(n=2,035)$ had some treatment action (Table 1). Treatment seeking was higher among female, children, urban residents and those from the least poor households. Among those who sought treatment, 95\% were treated with 'Westerntype' drugs, $43 \%$ were treated with anti-malarials while the remaining $57 \%$ were treated with other drugs, mainly antipyretics (Table 3, Additional File 1). Almost $53 \%$ of those febrile individuals who sought treatment were tested (Table 3) with testing rates higher among urban residents (70\%) compared to rural (42\%). Majority of treatments and tests were undertaken in government health facilities, mainly health centres and hospitals and only about $22 \%$ of all treatments were in the private sector. Among the 875 individuals who were treated for malaria, $44 \%$ were treated with the nationally recommended first-line therapy for uncomplicated malaria, AS $+\mathrm{SP}$ with $87 \%$ of these treatments occurring in the government sector (Table 4, Additional File 1). Chloroquine or SP, monotherapies not recommended for the management of malaria in the northern states of Sudan, were used to treat $13 \%$ of all malaria cases and quinine was reportedly administered for $5.0 \%$ (Table 4). Importantly $34 \%$ of all malaria treatments were reportedly managed using injectable artemether monotherapy which was more frequently obtained from public sector facilities, notably from higher order facilities such as hospitals and health centres (Table 4).

Of those individuals who reported a fever episode in the last two weeks and took action $40 \%$ took action within 24 hours and $67 \%$ within $48 \%$ hours. Of those that were treated within $24 / 48$ hours about $22 \%$ were treated with AS+SP, $16.1 \%$ with artemether, $2 \%$ with quinine, $5 \%$ with SP or CQ and about $55 \%$ with antipyretics and other non-anti-malarial drugs.

\section{Discussion}

Infection prevalence, as judged by RDT positivity rates, among 21,988 people sampled across 300 communities of the 15 northern states Sudan was very low, $1.8 \%$. These results have not been corrected using polymerase chain reaction detection, to account for the documented false positive rates $[13,32]$ and it is possible that the true prevalence between October and November 2009 is lower. The prevalence documented across eight northern states in 2005 using microscopy was $3.7 \%$ and it is possible that prevalence might be declining in the northern states of Sudan. However, such comparisons should be made with caution because of the acutely seasonal nature of transmission in semi-arid areas and the limitations of point-estimates of transmission in such areas. Nevertheless against a background of low malaria infection risk, nearly one in five people reported a febrile event during the two-week period prior to the survey. It is not clear what the majority of these events represent 
Table 3 Type of treatment and prevalence parasitological diagnosis before treatment by source among individuals who reported having fever in last two weeks and who took action $(N=2,035)$

\begin{tabular}{|c|c|c|c|c|}
\hline & $\begin{array}{r}\text { Use of any drug, \% } \\
(95 \% \mathrm{Cl})(\mathrm{n} / \mathrm{N}=1,935 / \\
2,035)\end{array}$ & $\begin{array}{r}\text { Use of anti-malarials, \% } \\
(95 \% \mathrm{Cl})(\mathrm{n} / \mathrm{N}=875 / \\
2,025)\end{array}$ & $\begin{array}{l}\text { Use of other drugs, \% } \\
(95 \% \mathrm{Cl})(\mathrm{n} / \mathrm{N}=1,060 / \\
2,035)\end{array}$ & $\begin{array}{r}\text { Parasitologically tested for malaria before } \\
\text { any treatment, \% (95\% Cl) }(\mathrm{n}=1,015 / \\
2,035)^{*}\end{array}$ \\
\hline \multirow[t]{2}{*}{ Overall } & $95.4(94.4-96.4)$ & $42.6(39.2-46.0)$ & $57.4(54.0-60.8)$ & $52.8(48.6-57.0)$ \\
\hline & & & & By treatment source \\
\hline \multicolumn{5}{|l|}{ Government } \\
\hline Hospital & $29.0(25.1-32.9)$ & $28.2(23.1-33.4)$ & $29.6(25.4-33.7)$ & $38.8(33.1-44.6)$ \\
\hline Health centre & $30.3(26.4-34.3)$ & $33.7(28.2-39.2)$ & $27.7(23.7-31.7)$ & $36.9(31.4-42.4)$ \\
\hline Basic health unit & $11.4(8.1-14.5)$ & $11.4(7.4-15.5)$ & $11.3(8.1-14.6)$ & $4.6(2.8-6.2)$ \\
\hline $\begin{array}{l}\text { Community } \\
\text { Health Worker }\end{array}$ & $6.9(4.5-9.3)$ & $5.9(3.2-8.6)$ & 7.7 (4.9-10.6) & $3.4(1.9-5.0)$ \\
\hline \multicolumn{5}{|l|}{ Private } \\
\hline $\begin{array}{l}\text { Health facility/ } \\
\text { pharmacy/drug } \\
\text { Store }\end{array}$ & $15.3(12.8-17.7)$ & $16.0(12.3-19.7)$ & 14.7 (12.0-17.5) & $15.2(11.6-18.9)$ \\
\hline Shop & $5.5(4.0-6.9)$ & $3.8(2.2-5.3)$ & $6.8(4.8-8.8)$ & $0.4(0.0-0.9)$ \\
\hline Other & $1.6(0.9-2.3)$ & $9.5(0.2-1.7)$ & $2.2(1.0-3.3)$ & $0.5(0.0-1.1)$ \\
\hline
\end{tabular}

Proportions are weighted and cluster adjusted.

*Individuals tested for malaria when reporting at a health facility with fever. $57 \%$ of these received anti-malarials compared to $29 \%$ of those who were not tested. It was not possible to discern whether only the positive cases were treated with anti-malarials because of problems with recall and incompleteness of test status.

in clinical and public health terms as almost $60 \%$ of febrile people do not seek any treatment and are apparently well during the survey interview. However $40 \%$ did seek treatment and almost half of these treatment actions included the use of anti-malarials. The prevalence of "malaria" treatment is higher than a point prevalence of infection and may suggest a degree of over-treatment. However, it is also important to note that the prevalence of infection is over six-times higher $(\mathrm{OR}=6.2$; Table 2$)$ among patients with a fever on the day of the survey and in an area where transmission intensity is low and the acquisition of functional clinical immunity to new infections is low [33], infection may be more directly related to symptoms, as such the prevalence of fever and infection is closer to the reported anti-malarial use recorded during this survey. Clearly this presumes that those fevers that don't seek treatment are not associated with malaria and those who seek treatment are appropriately defined as malaria. Neither of these caveats can be tested directly through cross-sectional surveys.

When treatment for fevers was sought, over $70 \%$ of patients were managed at the Government's health

Table 4 Type of anti-malarials used by source among individuals who reported having fever in last two weeks and who were treated for malaria $(\mathrm{N}=\mathbf{8 7 5})$.

\begin{tabular}{|c|c|c|c|c|c|}
\hline & \multicolumn{5}{|c|}{ Anti-malarial type } \\
\hline & $\begin{array}{r}\mathrm{AS}+\mathrm{SP}(\mathrm{n}= \\
382)\end{array}$ & $\begin{array}{r}\text { SP or Chloroquine }(\mathrm{n}= \\
122)\end{array}$ & $\begin{array}{r}\text { Quinine ( } \mathrm{n}= \\
39)\end{array}$ & $\begin{array}{r}\text { Artemether }(\mathrm{n}= \\
296)\end{array}$ & $\begin{array}{r}\text { Other }^{\dagger}(n= \\
36)\end{array}$ \\
\hline Overall & $43.9(39.6-48.2)$ & $13.4(10.6-16.2)$ & $4.5(2.8-6.1)$ & $33.7(30.0-37.4)$ & $4.6(2.7-6.5)$ \\
\hline \multicolumn{6}{|l|}{ By treatment source } \\
\hline \multicolumn{6}{|l|}{ Government } \\
\hline Hospital & $29.0(21.2-36.8)$ & $20.3(11.3-29.3)$ & $50.2(27.8-72.6)$ & $28.4(21.4-35.3)$ & $21.4(7.6-35.1)$ \\
\hline Health centre & $36.5(27.3-45.7)$ & $24.0(14.7-33.2)$ & $33.6(11.1-56.1)$ & $35.8(29.2-42.4)$ & $20.2(4.7-35.8)$ \\
\hline Basic health unit & $10.5(4.9-16.0)$ & $14.6(6.6-22.7)$ & $5.4(-0.0-11.1)$ & $13.7(7.6-19.7)$ & \\
\hline Community Health Worker & $7.0(2.1-11.8)$ & $5.8(0.7-11.0)$ & $7.2(-0.2-14.6)$ & $4.4(1.7-7.2)$ & $5.5(-5.0-15.9)$ \\
\hline \multicolumn{6}{|l|}{ Private } \\
\hline $\begin{array}{l}\text { Health facility/pharmacy/drug } \\
\text { Store }\end{array}$ & $14.6(9.3-20.0)$ & $20.0(10.9-29.1)$ & $2.1(-1.9-6.2)$ & $14.7(10.3-19.1)$ & $40.2(18.3-62.1)$ \\
\hline Shop & $1.6(0.3-28.6)$ & $15.2(7.3-23.2)$ & $1.4(-1.4-4.2)$ & $1.1(-0.6-2.9)$ & $12.7(-4.3-29.9)$ \\
\hline Other & $0.7(-0.0-1.7)$ & & & $1.8(-0.0-3.8)$ & \\
\hline
\end{tabular}

Proportions are weighted and cluster adjusted.

${ }^{\dagger} 13$ individuals took $\mathrm{AL}, 23$ took unspecified anti-malarial drugs. 
facilities that are managed by State health authorities. The use of the private retail sector in the northern states of Sudan is not as prolific as described in many other African settings [34]. Partly as a consequence of the high government sector use, the most striking observation was the wide-spread reported access to parasitological diagnosis among febrile respondents who sought treatment (53\%; Table 3). Strengthened laboratory support for malaria diagnosis has been an important part of the recent malaria case-management strategy [23]. It was not possible to stratify analysis on the reported test results as these data were incomplete and were not verified against patient or care-giver notes to distinguish true test positive results from the results told to the patients. However, what is clear is that parasitological testing per se did influence the prescriptions made and a higher proportion of tested patients received the nationally recommended first-line treatment compared for uncomplicated malaria to those not tested for malaria (data not shown). Separate studies are underway to examine the quality of care and prescription practices among health workers in the government health sector to investigate prescribers' adherence to parasitological test results and the associated prescriptions. The international milestones for successful implementation of case-management are currently anchored around $60 \%$, $80 \%$ or universal treatment of all fevers with anti-malarial drugs within 24/48 hours [35-37]. The Sudan National Malaria Strategy for the northern states outlines the ambition that by 2012 " $80 \%$ of malaria patients will receive prompt and effective treatment" [23]. In addition the current national malaria strategy aims at reaching $100 \%$ laboratory confirmation of reported malaria incidence by 2010 [23]. A more adequate target for Sudan and many countries in Africa is that all fevers are tested for malaria and all those reported as positive for malaria infection are treated with national first-line recommended therapy. That only $19 \%$ of fevers (and $45 \%$ of those who were treated with anti-malarials) were treated with nationally recommended AS+SP and that only $14 \%$ were managed with AS+SP within 48 hours is not a failure to reach established milestones as most fevers are not malaria and thus should not be held to account as a failure. Indeed it could be argued that the fewer fever/anti-malarial drug exposures the greater the success of programmes promoting effective diagnostic strategies.

Of greatest concern was the reported use of artemether, available in injectable forms at Government clinics, despite an international ban on its use to manage uncomplicated malaria by the World Health Organization in 2006 [38]. The use of artemether in Sudan has been attributed to a belief by some prescribers and patients that injections have a stronger effect and work faster than oral medications and that there may be patient pressure to use these medicines $[39,40]$. Furthermore parasitological diagnosis of malaria was a predictor of artemether use, where patients were almost 3 times more likely to receive this drug if tested compared to if no parasitological test was done (data not shown). Chloroquine and SP continue to be available at government clinics and are prescribed, more frequently if no parasitological diagnosis is attempted than when malaria testing is performed, despite the reported wide-spread resistance across Sudan to both these mono-therapies $[22,41,42]$. Non-adherence to national standard treatment guidelines at the point of care is common across many settings in Africa [43-47], previously reported in Sudan [48] and their reasons and determinants complex $[45,49]$. Exploring the prescription practices and patient treatment actions demands a more rigorous combination of facility and community-based qualitative and quantitative investigations than was possible through the large-scale single cross-sectional sample survey described here.

About $67 \%$ of fevers that sought treatment in the current study were treated after 48 hours of onset of symptoms. Similar findings have been reported in Sudan where $40 \%$ of the fever cases sought treatment after 72 hours of onset of symptoms and a mean delay of 67.8 hours before attending a health facility $[22,50]$. Lack of money, waiting for improvement, low coverage with health facilities, dissatisfaction with services, difficulty to reach the facilities especially during rainy season, and waiting for the effect of traditional remedies have been highlighted as some of the reasons for delayed treatment $[26,51]$.

\section{Conclusions}

This study demonstrates that fever prevalence in the Sudan is low and with a $P$. falciparum infection prevalence of only $1.8 \%$, the proportion of fevers attributable to malaria would also be extremely low. Consequently, parasitological diagnosis of malaria at all levels of the health system must become part of the malaria case management policy. Although the current testing rate of fevers of $53 \%$ is higher than those of most African countries, it still remains low largely because microscopy in the Sudan is limited to hospitals and health centres [52] and RDTs have not been scaled up nationally. Ongoing revision of the national malaria strategy aims to commit the northern states of the Sudan to parasitological diagnosis of all fevers which will be supported with rapid scale-up of RDTs in the all public health facilities, which provide almost $80 \%$ of all fever treatments [Abdalla, Personal Communication]. Concerns remain, however, on the types of anti-malarials used for the treatment of fevers with both chloroquine and SP still in circulation, both of which have failed in the northern states of Sudan in the treatment of $P$. falciparum infections, although chloroquine is still used for the treatment of 
P. vivax malaria in the country. Importantly, Sudan must urgently focus attention on stopping the widespread use of artemether for fever treatment, a monotherapy banned internationally by the World Health Organization for treatment of uncomplicated malaria, to avoid the emergence of resistance of artemisinin which could lead to devastating consequences both in the Sudan and the rest of Africa. Interestingly, majority of patients who received artemether have obtained this drug from the public health sector and an investigation of the reasons behind this practice, given that the health workers from this sector have had extensive training in malaria case-management, should be undertaken.

\section{Additional material}

Additional file 1: A summary of numerators (n) and denominators (N) for Tables 1, 3 and 4 in the main text The additional file presents the numbers of persons: interviewed during the 2009 national malaria indicator survey in the northern states of Sudan; with fever in the last two weeks and on the day of survey; sought treatment for fever; tested for malaria; positive for malaria; used drugs; used antimalarials; and by type of antimalarial.

\section{Abbreviations}

ACT: artemisinin-based combination therapy; AS+SP: artesunate (AS) plus sulphadoxine/pyrimethamine (SP); GFATM: Global Fund to Fight AIDS, Tuberculosis and Malaria; LLIN: long lasting insecticide treated nets; MIS: Malaria Indicator Survey; NMCP: National Malaria Control Programme; RBMMERG: Roll back Malaria-Monitoring and Evaluation Reference Group; WHO/ EMRO: World Health Organization-Eastern Mediterranean Regional Office (WHO-EMRO); RDT: Rapid Diagnostic Test; PAU: Popular administrative unit; FMoH: Federal Ministry of Health.

\section{Acknowledgements}

The authors thank all departments within the Federal Ministry of Health involved in the survey and the Central Bureau of Statistics for providing us with sampling frame for the survey. We also thank Drs Emelda Okiro and Dejan Zurovac for their comments on earlier versions the manuscript. Funding

The national malaria survey was funded using Global Fund to Fight TB, AIDS and Malaria money via the UNDP Sudan (Prinicpal Recipient) and WHOEMRO/RBM (sub-Recipient) for funding this survey. AMN is supported by the Wellcome Trust as a Research Training Fellow (\#081829). RWS is supported by the Wellcome Trust as Principal Research Fellow (\#079080) which also supports SG. The funders were not involved in design of study, analysis of data and drafting of manuscript.

\section{Author details}

${ }^{1}$ National Malaria Control Programme, Federal Ministry of Health, P.O. Box 1204 Khartoum, Sudan. ${ }^{2}$ Malaria Public Health \& Epidemiology Group, Centre for Geographic Medicine Research - Coast, Kenya Medical Research Institute/ Wellcome Trust Research Programme, P.O. Box 43640, 00100 GPO, Nairobi, Kenya. ${ }^{3}$ Centre for Tropical Medicine, Nuffield Department of Clinical Medicine, University of Oxford, CCVTM, Oxford OX3 7LJ, UK. ${ }^{4}$ Directorate General of Preventive Medicine and PHC, Federal Ministry of Health, P.O. Box 1204, Khartoum, Sudan.

\section{Authors' contributions}

KAE was involved in design and development of survey tools, implementation of survey, and collection of data and drafting of the manuscript. AMN designed the study, collected, cleaned and analysed the data and participated in drafting the manuscript. SG reanalyzed the data and participated in drafting the manuscript. TMA was involved in design and development of survey tools, implementation of survey, and collection of data and drafting of the manuscript. EMM has participated in the design and planning of the study. He has revised the manuscript as well. RWS conceived the questions for this manuscript and provided direction on analysis and drafting the manuscript.

\section{Competing interests}

The authors declare that they have no competing interests.

Received: 21 February 2011 Accepted: 15 May 2011

Published: 15 May 2011

\section{References}

1. Rougemont A, Breslow N, Brenner E, Moret AL, Dumbo O, Dolo A, Soula G, Perrin L: Epidemiological basis for clinical diagnosis of childhood malaria in endemic zone in West Africa. Lancet 1991, 338:1292-1295.

2. Redd SC, Kazembe PN, Luby SP, Nwanyanwu O, Hightower AW, Ziba C, Wirima JJ, Chitsulo L, Franco C, Olivar M: Clinical algorithm for treatment of Plasmodium falciparum malaria in children. Lancet 1996, 347:223-227.

3. Gove S: Integrated management of childhood illness by outpatient health workers: technical basis and overview. The WHO Working Group on Guidelines for Integrated Management of the Sick Child. Bull World Health Organ 1997, 75(Suppl 1):7-24.

4. Font $\mathrm{F}$, Alonso Gonzalez M, Nathan R, Kimario J, Lwilla F, Ascaso C, Tanner M, Menendez C, Alonso PL: Diagnostic accuracy and case management of clinical malaria in the primary health services of a rural area in south-eastern Tanzania. Trop Med Int Health 2001, 6:423-428.

5. Chandramohan D, Jaffar S, Greenwood B: Use of clinical algorithms for diagnosing malaria. Trop Med Int Health 2002, 7:45-52.

6. Chandler Cl, Chonya S, Boniface G, Juma K, Reyburn H, Whitty CJ: The importance of context in malaria diagnosis and treatment decisions - a quantitative analysis of observed clinical encounters in Tanzania. Trop Med Int Health 2008, 13:1131-1142.

7. World Health Organization: Guidelines for the treatment of malaria. World Health Organization, Geneva, Switzerland i, 2010.

8. Bosman A, Mendis KM: A major transition in malaria treatment: the adoption and deployment of artemisinin-based combination therapies. Am J Trop Med Hyg 2007, 77:193-197.

9. Okiro EA, Snow RW: The relationship between reported fever and Plasmodium falciparum infection in African children. Malar / 9:99.

10. Gething PW, Kirui VC, Alegana VA, Okiro EA, Noor AM, Snow RW: Estimating the number of paediatric fevers associated with malaria infection presenting to Africa's public health sector in 2007. PLoS Med 2010, 7(7):e1000301.

11. D'Acremont V, Lengeler C, Genton B: Reduction in the proportion of fevers associated with Plasmodium falciparum parasitaemia in Africa: a systematic review. Malar J 2010, 9:240.

12. Gosling RD, Drakeley CJ, Mwita A, Chandramohan D: Presumptive treatment of fever cases as malaria: help or hindrance for malaria control? Malar J 2008, 7:132.

13. World Health Organization: Malaria rapid diagnostic test performance: results of WHO product testing of malaria RDTs: round 1 (2008) World Health Organization Special Programme for Tropical Diseases; 2009.

14. Drakeley $C$, Reyburn $\mathrm{H}$ : Out with the old, in with the new: the utility of rapid diagnostic tests for malaria diagnosis in Africa. Trans $R$ Soc Trop Med 2009, 103:333-337.

15. Rafael ME, Taylor T, Magill A, Lim Y, Girosi F, Allan R: Reducing the burden of childhood malaria in Africa: the role of improved diagnostics. Nature 2006, 444:48.

16. El Gaddal AA: The Blue Nile Health Project: a comprehensive approach to the prevention and control of water-associated diseases in irrigated schemes of the Sudan. J Trop Med Hyg 1985, 88:47-56.

17. Federal Ministry of Health/National Malaria Control Programme: Malaria prevalence and coverage indicators survey Sudan - October 2005 2005, Final Report - December.

18. Abdalla SI, Malik EM, Ali KM: The burden of malaria in Sudan: incidence, mortality and disability-adjusted life - years. Malar J 2007, 6:97.

19. Hay SI, Guerra CA, Gething PW, Patil AP, Tatem AJ, Noor AM, Kabaria CW, Manh BH, Elyazar IRF, Brooker S, Smith DL, Moyeed RA, Snow RW: A world 
malaria map: Plasmodium falciparum endemicity in 2007. PLoS Med 2009, 6:e1000048.

20. Guerra CA, Howes RE, Patil AP, Gething PW, Van Boeckel TP, Temperley WH, Kabaria CW, Tatem AJ, Manh BH, Elyazar IRF, Baird JK, Snow RW, Hay SI: The international limits and population at risk of Plasmodium vivax transmission in 2009 PLOS NTD. 2010, 4:e774.

21. Federal Ministry of Health: Malaria Indicator Survey 2009 in the Northern states of the Sudan Submitted to the World Health Organization, Eastern Mediterranean Regional Office, Cairo, Egypt; 2010.

22. Malik EM, Hanafi K, Ali SH, Ahmed ES, Mohamed KA: Treatment-seeking behaviour for malaria in children under five years of age: implication for home management in rural areas with high seasonal transmission in Sudan. Malar J 2006, 5:60.

23. Federal Ministry of Health: National Malaria Strategic Plan 2007-2012 Khartoum; 2006.

24. van den Broek I, Amsalu R, Balasegaram M, Hepple P, Alemu E, Hussein el B, Al-Faith M, Montgomery J, Checchi F: Efficacy of two artemisinin combination therapies for uncomplicated falciparum malaria in children under 5 years, Malakal, Upper Nile, Sudan. Malar J 2005, 4:14.

25. Salah MT, Mohammed MM, Himeidan YE, Malik EM, Elbashir MI, Adam I: A randomized comparison of sulphadoxine-pyrimethamine and combination of sulphadoxine pyrimethamine with chloroquine in the treatment of uncomplicated falciparum malaria in Eastern Sudan. Saudi Med J 2005, 26:147-148.

26. Elmardi KA, Malik EM, Abdelgadir T, Ali SH, Elsyed AH, Mudather MA, Elhassan AH, Adam I: Feasibility and acceptability of home-based management of malaria strategy adapted to Sudan's conditions using artemisinin-based combination therapy and rapid diagnostic test. Malar J 2009, 8:39.

27. Mukhtar EA, Gadalla NB, El-Zaki SE, Mukhtar I, Mansour FA, Babiker A, ElSayed BB: A comparative study on the efficacy of artesunate plus sulphadoxine/pyrimethamine versus artemether-lumefantrine in eastern Sudan. Malar J 2007, 6:92.

28. GFATM:[http://portfolio.theglobalfund.org/Country/Index/SUD?lang=en], (accessed 16 September 2010).

29. RBM-MERG: Malaria Indicator Survey: Basic Documentation for Survey Design and Implementation 2010 [http://www.rbm.who.int/mechanisms/merg. html\#expand_node].

30. Amin AA, Marsh V, Noor AM, Ochola SA, Snow RW: The use of formal and informal curative services in the management of paediatric fever in four districts in Kenya. Trop Med Int Health 2003, 8:1143-1152.

31. Gitonga CW, Amin AA, Ajanga A, Kangwana BB, Noor AM, Snow RW: The use of artemether-lumefantrine by febrile children following national implementation of a revised drug policy in Kenya. Trop Med Int Health 2008, 13:487-494.

32. Okell LC, Ghani AC, Lyons E, Drakeley CJ: Submicroscopic infection in Plasmodium falciparum-endemic populations: a systematic review and meta-analysis. J Infect Dis 2009, 200:1509-1517.

33. Snow RW, Marsh K: Malaria in Africa: progress and prospects in the decade since the Abuja Declaration. Lancet 2010, 376:137-139.

34. Goodman C, Brieger W, Unwin A, Mills A, Meeks S, Greer G: Medicine sellers and malaria treatment in sub-Saharan Africa: what do they do and how can their practice be improved? Am J Trop Med Hyg 2007, 77:203-218.

35. Roll Back Malaria: The Abuja declaration and the plan of action. An extract from the African Summit on Roll Back Malaria, Abuja, 25 April 2000 Geneva: Roll Back Malaria (RBM);11, (WHO/CDS/RBM/2000.17).

36. Roll Back Malaria: Global Strategic Plan: Roll Back Malaria 2005-2015 Roll Back Malaria Partnership, World Health Organization, Geneva, Switzerland; 2005.

37. Roll Back Malaria: The Global Malaria Action Plan Roll Back Malaria Partnership, World Health Organization, Geneva; 2008.

38. WHO: 2006 [http://www.who.int/malaria/publications/atoz/ meeting_briefing19april/en/index.html].

39. Abdel-Hameed AA: Malaria case management at the community level in Gazira, Sudan. Afr J Med Sci 2000, 30:43-46.

40. Mannan AA, Malik EM, Ali KM: Anti-malarial prescribing and dispensing practices in health centres of Khartoum state, 2003-04. East Mediterr Health J 2009, 15:122-128.

41. Adam I, Elhardello OA, Elhadi MO, Abdalla E, Elmardi KA, Jansen FH: The antischistosomal efficacies of artesunate-sulfamethoxypyrazinepyrimethamine and artemether-lumefantrine administered as treatment for uncomplicated, Plasmodium falciparum malaria. Ann Trop Med Parasitol 2008, 102:39-44.

42. Elamin SB, Malik el FM, Ahmed el DS, Elabadil EK, Mohamad TA: Efficacy of chloroquine and sulfadoxine/pyrimethamine mono- and combined therapy against falciparum malaria in Sudan. East Mediterr Health J 2007, 13:25-34.

43. Rowe AK, Hamel MJ, Flanders WD, Doutizanga R, Ndoyo J, Deming MS: Predictors of correct treatment of children with fever seen at outpatient health facilities in the Central African Republic. Am J Epi 2000, 151:1029-1035.

44. Eriksen J, Tomson G, Mujinja P, et al: Assessing health worker performance in malaria case management of underfives at health facilities in a rural Tanzanian district. Trop Med Int Health 2007, 12:52-61.

45. Zurovac D, Rowe AK: Quality of treatment for febrile illness among children at outpatient facilities in sub-Saharan Africa. Ann Trop Med Parasitol 2006, 100:283-296.

46. Zurovac D, Ndhlovu M, Sipilinyambe N, Chanda P, Hamer DH, Simon JL, Snow RW: Paediatric malaria case-management with artemetherlumefantrine in Zambia: a repeat cross-sectional study. Malar J 2007, 6: e31.

47. Zurovac D, Tibenderana JK, Nankabirwa J, Ssekitooleko J, Njogu JN, Talisuna AO, Rwakimari JB, Meek S, Snow RW: Malaria case management under ACT treatment policy in Uganda. Mala J 2008, 7:e181.

48. Yousif MA, Adeel AA: Anti-malarials prescribing patterns in Gezira State: precepts and practices. East Mediterr Health J 2000, 6:939-947.

49. Rowe AK, de Savigny D, Lanata CF, Victora CG: How can we achieve and maintain high-quality performance of health workers in low-resource settings? Lancet 2005, 366:1026-1035.

50. Mustafa HS, Malik EM, Tuok HT, Mohamed AA, Julla Al, Bassili A: Malaria preventive measures, health care seeking behaviour and malaria burden in different epidemiological settings in Sudan. Trop Med Int Health 2009, 14:1488-1495.

51. Saeed IE, Ahmed ES: Determinants of acquiring malaria among displaced people in Khartoum state, Sudan. East Mediterr Health J 2003, 9:581-592.

52. Federal Ministry of Health: Malaria Quality of Care Survey in 2009 in the Northern states of the Sudan Submitted to the World Health Organization, Eastern Mediterranean Regional Office, Cairo, Egypt; 2010.

doi:10.1186/1475-2875-10-128

Cite this article as: Elmardi et al: Self-reported fever, treatment actions and malaria infection prevalence in the northern states of Sudan. Malaria Journal 2011 10:128.

\section{Submit your next manuscript to BioMed Central and take full advantage of:}

- Convenient online submission

- Thorough peer review

- No space constraints or color figure charges

- Immediate publication on acceptance

- Inclusion in PubMed, CAS, Scopus and Google Scholar

- Research which is freely available for redistribution

Submit your manuscript at www.biomedcentral.com/submit
C Biomed Central 